\title{
LAS NOVELAS DE ALEJO CARPENTIER \\ Y LA REALIDAD MARAVILLOSA
}

\author{
POR \\ PAUL VERDEVOYE \\ Université de Paris, III, Sorbonne Nouvelle
}

Eı 8 de abril de 1948, en un artículo de El Nacional, de Caracas, Alejo Carpentier quiso cifrar la especificidad del mundo hispanoamericano en dos fórmulas equivalentes: «la realidad maravillosa» y «lo real maravilloso». Se sabe que dicho artículo fue reproducido al año siguiente en su novela El reino de este mundo. Desde entonces ambas fórmulas se hicieron famosas.

Ya que, unos veinte años después, A. Carpentier publicó de nuevo este artículo (en Tientos y diferencias), es lícito pensar que el novelista se mantuvo fiel a su interpretación del principio. Esta permanencia cobra mayor importancia aún cuando comprobamos que toda la obra novelesca de Carpentier ha sido inspirada en esa realidad, y que, desde los primeros libros, se notan en ella una serie de signos seleccionados cuidadosamente por el narrador para que dicha realidad tenga visos maravillosos. De modo que, remedando al novelista, podríamos hablar de su «escritura maravillosa».

En el prólogo a El reino de este mundo se distinguen sobre todo dos motivos principales. Primero, un motivo polémico, que opone la «realidad maravillosa» que ha embrujado al novelista en Haití, a lo maravilloso que, según dice, "caracterizó ciertas literaturas europeas de estos últimos treinta años». De contrapunto, se viene insinuando, para imponerse finalmente, la exaltación de un maravilloso auténtico en la historia de América.

Aquella auténtica maravilla consiste en lo que el mismo ensayista llama un milagro, "una revelación privilegiada de la realidad, de una iluminación inhabitual o singularmente favorecedora de las inadvertidas riquezas de la realidad, de una ampliación de las escalas y categorías de la realidad, percibidas con particular intensidad en virtud de una exalta- 
ción del espíritu que lo conduce a un modo de estado límite». En la afirmación siguiente: «la sensación de lo maravilloso presupone una fe», se subraya, sin que Carpentier se dé cuenta de ello tal vez, el carácter subjetivo de una definición de la realidad que estriba en un fervor personal.

Esta realidad maravillosa, Carpentier no la siente sólo en Haití, sino en todo el continente hispanoamericano: «(...) ¿qué es la historia de América toda sino una crónica de lo real maravilloso?»

\section{Definiciones}

Una fórmula parecida - aunque de significación diferente a pesar de las apariencias formales- había sido aplicada, en 1925, al postexpresionismo alemán por Franz Roh, y adoptada más tarde por Arturo Uslar Pietri, quien encontraba en el cuento venezolano «una adivinación poética o una negación poética de la realidad. Lo que a falta de otra palabra podría llamarse un realismo mágico» ${ }^{1}$. Esta fórmula había sido ampliamente difundida por la traducción al castellano del libro de Roh, que en la versión publicada en 1927 por la Revista de Occidente se titulaba precisamente Realismo mágico.

Volvamos ahora a la diferencia que hace Carpentier entre lo maravilloso en las literaturas europeas «de los últimos treinta años» y lo maravilloso hispanoamericano. Aquel período abarca un movimiento muy admirado por Carpentier, y cuya influencia en su obra es patente, por lo menos a través de la importancia que el novelista cubano atribuye a lo maravilloso, elemento puesto sobre el tapete por André Breton en su $\mathrm{Ma}$ nifeste du surréalisme. Conviene reconocer, sin embargo, que dos elementos, por lo menos, introducen una diferencia esencial entre la realidad maravillosa de Carpentier y el surrealismo. Uno de ellos ha sido destacado por Emir Rodríguez Monegal: es la fe; «la sensación de lo maravilloso presupone una fe», declara Carpentier. El otro elemento es el telurismo, el vínculo con la tierra y, por consiguiente, con lo concreto, lo circunstancial, to histórico.

\section{SignOS EXTERIORES DE LA REALIDAD MARAVILlOSA}

Esta realidad maravillosa se expresa por signos reconocibles en la escritura de Carpentier. Los más evidentes se manifiestan en los títulos.

\footnotetext{
${ }^{1}$ Letras y hombres de Venezuela, 1948, p. 267.
} 
Desde la primera novela, en 1933, Carpentier sorprende al lector: EcuéYamba-O ${ }^{2}$. El lector profano comprende después que se trata de una fórmula mágica salmodiada en una ceremonia iniciática. Carpentier no repite esta experiencia; prefiere proponer títulos que requieren por lo menos dos interpretaciones. El reino de este mundo invierte el sentido de la frase pronunciada por Cristo: "Mi reino no es de este mundo», y simboliza al mismo tiempo los horrores cometidos por el rey de Haití. Con Los pasos perdidos, la ambigüedad es más sutil: Carpentier se vale del título de una novela de André Breton, y a la par designa los pasos del civilizado que ha vuelto a encontrar en la selva, en el mundo primitivo, aunque por poco tiempo, la razón primordial de su ser. El acoso significa a la vez la persecución de la que es víctima el personaje de la novela y el hostigamiento interior producido por la memoria del pasado. El siglo de las luces evidencia las contradicciones de una civilización que ha inventado la guillotina y que, después de suprimir la esclavitud, la restablece. En El recurso del método, Carpentier remeda a Descartes y plantea de nuevo, a su manera, el conflicto entre civilización y barbarie. Concierto barroco conjuga armoniosamente la música de Vivaldi y la vida barroca de los personajes. La consagración de la primavera es evidentemente el título de la partitura de Stravinsky, y sobreentiende también el nacimiento de la revolución cubana. Para El arpa y la sombra, Carpentier se vale de la primera y la última palabras de un fragmento de leyenda y sugiere un juego entre el instrumento de música, que simboliza aquí la vida o la historia, y la sombra, que reinventa la historia.

Esas ambivalencias definen de alguna manera la ironía de Carpentier, que como cualquier ironía, tiene dobles intenciones.

Encuéntranse signos de lo maravilloso en el léxico impresionista del escritor. En Ecué-Yamba-O el deseo de embrujar al lector era tan fuerte que el novelista añadió un glosario, en el que se codeaban gran número de palabras insólitas. En las otras novelas no hay glosario, pero abundan, en cambio, las palabras claves, que, por su repetición, dan una significación fuera de lo común a paisajes, situaciones o personajes. Es

${ }^{2}$ Las novelas de A. Carpentier se citan por las siguientes ediciones: Ecué-Yamba-O, novela afro-cubana (Buenos Aires: Editorial Xanandú, 1968; 1.a ed., 1933). El reino de este mundo (Barcelona: Editorial Seix Barral, 1967; 1. ${ }^{\mathrm{e} e d}$. 1949). Los pasos perdidos (México: Cía. General de Ediciones, 1969; 1.² ed., 1953). El acoso (Buenos Aires: Editorial Losada, 1956). El siglo de las luces (La Habana: Ediciones R, 1963; 1. a ed., 1962); El recurso del método (México-Madrid-Buenos Aires: Siglo Veintiuno, 1975; 1. ${ }^{a}$ ed., 1974). Concierto barroco (México-Madrid-Buenos Aires: Siglo Veintiuno, 1974). La consagración de la primavera (Madrid: Siglo Veintiuno de España, 1978). El arpa y la sombra (México-Madrid-Buenos Aires-Bogotá: 1979). 
fácil sacar de sus novelas un muestrario de vocablos que tienden a crear un ambiente maravilloso: signo, secreto, liturgia, milagro, arcano, mística. Más numerosos aún son los adjetivos de este tipo, que agregan a las cosas un aura insólita: extraño, prodigioso, imaginario, fantástico, secreto, escondido, oculto, diabólico, esotérico, ritual, irreal, enigmático, misterioso.

Su prosa se metaforiza con términos sacados de la música, la pintura, la arquitectura, la religión, la danza. La transferencia de un mundo a otro, por la metamorfosis de los objetos, la humanización de las cosas, de las plantas, de los animales, transforma casi permanentemente el universo en otro analógico, sorprendente; maravilloso, pues.

Estas «correspondencias» prodigiosas y estos asombros no le bastan a Carpentier para reducir a prosa su visión maravillosa y maravillada de América. A la imaginación visual se une su sensibilidad a los efectos acústicos de las palabras, juntándolas a veces como para reproducir la música de las cosas. Concierto barroco, por ejemplo, se abre con una frase cuyo efectismo musical es patente por las aliteraciones, combinaciones sonoras y rimas internas: «De plata los delgados cuchillos, los finos tenedores; de plata los platos donde un árbol de plata labrada en la concavidad de sus platas recogía el jugo de los asados; de plata los platos fruteros, de tres bandejas redondas; coronadas por una granada de plata», etc.

Y como broche de oro, culmina este bien llamado «concierto» en una frase final cuyo ritmo se parte en dos eneasílabos asonantados (además de la abundancia de $r$ ): «Las horas dadas por los Moros / de la Torre del Orologio». Gracias a la imaginación creadora del escritor-compositor, estos floreos, esta orquestación, producen la sensación de una «surrealidad» maravillosa, que, en el mundo de los sonidos, no dista mucho del sentido que a dicha palabra daba Breton en su Manifeste.

\section{CUlTura Y REALIDAD MARAVILlosa}

A esta realidad maravillosa se asocia la cultura de Carpentier. Esta cultura es la de muchos de sus personajes. Esteban, en El siglo de las luces, es aficionado a lo imaginario, a lo fantástico; con Sofía se pasa el tiempo leyendo novelas, grimorios, tratados herméticos. El dictador de El recurso del método es un hombre experto en literatura. Vera, la bailarina de La consagración de la primavera (su nombre se encuentra en consonancia con la última sílaba del título: ¿mera coincidencia?), pertenece a la antigua y refinada burguesía rusa; sus dos amantes sucesivos, 
Jean-Claude y Enrique, son intelectuales; las queridas de este último son: una joven estudiante alemana y Teresa, mujer del medio culto de La Habana. Los personajes o narradores de otras novelas citan a cada rato obras de literatura, historia, arte. Los pasos perdidos, El reino de este mundo y El siglo de las luces se alimentan con crónicas y documentos de archivos.

Se podría hacer un libro voluminoso juntando los epígrafes, las citas, las alusiones literarias de las obras de Carpentier. Lo importante es preguntarse qué retiene el novelista de sus lecturas: sobre todo, lo que está fuera de lo común y cotidiano. De Rusia, por ejemplo, en La consagración de la primavera, las danzas primitivas que inspiraron a Stravinsky. Insistiendo en lo raro, Carpentier encabeza esta novela con un fragmento de Las aventuras de Alicia en el país de las maravillas. De Inglaterra, recuerda también los extraños cuadros de Turner que representan una locomotora en la neblina, o una lluvia inesperada (Concierto barroco), o el Prometeo de Shelley (Los pasos perdidos).

De Alemania, en esta última novela, el novelista se acuerda de un poema de Schiller evocando la entrada en un santuario, y en $L a$ consagración de la primavera, mientras piensa en su amante, Vera se recita para sus adentros los himnos de Novalis.

En el mundo hispánico, Carpentier elige las costumbres extrañamente humanas de los animales descritos por Isidoro de Sevilla, los relatos maravillados de Colón, o las alegorías de Gracián (El arpa y la sombra). Empieza El reino de este mundo con un diálogo entre el Demonio y la Providencia, sacado de una alegoría de Lope de Vega. Y si apela al folklore, transcribe viejos romances tradicionales (Los pasos perdidos), o copia, en El siglo de las luces, la célebre profecía de Torres Villarroel, que había predicho, en medio del siglo XVIII, la muerte de Luis XVI en el cadalso.

Por una irrisión visible en el título de $E l$ recurso del método, en la literatura francesa, Carpentier se da el gusto de buscar lo menos cartesiano. Así, El reino de este mundo y Los pasos perdidos contienen referencias a Atala, o a Paul et Virginie; Concierto barroco alude a las Confesiones de Rousseau y a las Lettres italiennes, del Président Charles de Brosses. Uno de los capítulos de $E l$ reino de este mundo se titula asombrosamente «La hija de Minos y de Pasifae», y se reproducen en él varios versos de la Fedra de Racine.

Esta última referencia nos lleva al mundo antiguo, también aprovechado por el novelista. Como botón de muestra, baste recordar algunas líneas de Medea, la tragedia de Séneca, en El arpa y la sombra, y la pre- 
sencia sorprendente, en Los pasos perdidos, del griego, lector asiduo de la Odisea.

La América precolombina también, pero mucho menos, enriquece asimismo la materia literaria de Carpentier con el Libro de Chilam Balam y el Popol $V u h$, que abren los capítulos de Los pasos perdidos, como para introducir la cosmogonía indígena en la evocación de la selva.

Este rápido vistazo basta para destacar la función que Carpentier quiere que desempeñe lo que podríamos 1lamar el «sobretexto», destinado a exaltar el carácter maravilloso del discurso. Acrecienta aún este efecto la utilización de textos bíblicos; "las veladas se consagraban a la lectura de la vieja Biblia», dice el principal protagonista de Los pasos perdidos (p. 64). Las descripciones de la naturaleza americana recuerdan el principio del Génesis, cuya influencia es obvia, por ejemplo, en el capítulo sexto de $E l$ siglo de las luces, cuando el novelista evoca «el Primer Mar de la Creación» (p. 357), o las islas del Caribe a las que Esteban, por primera vez, da un nombre (p. 233). Pero Carpentier no se contenta con esmaltar su prosa con referencias sacadas de la Biblia $\mathfrak{u}$ otros textos sagrados. Como algunos poetas modernistas que adornaron sus poemas con citas latinas para infundirles algún misterio religioso, el novelista cubano parece atento al prestigio litúrgico de la misa católica recitada en la lengua de los romanos. Así, en El reino de este mundo inserta fragmentos en latín de la misa del 15 de agosto, o titula dos capítulos de la misma novela «De profundis» y "Agnus Dei». En Los pasos perdidos reproduce el final de la misa y una larga secuencia de un canto gregoriano. Pero no se limita al latín de textos litúrgicos, ya que en El arpa y la sombra transcribe en su texto original la proposición de canonización de Cristóbal Colón.

En muchos casos Carpentier traduce al castellano los textos extranjeros; pero ocurre que deja en el idioma original partes de un poema de Schiller (Los pasos perdidos) o de Dante (El arpa y la sombra); o de autores franceses - los más citados-, como el verso leit motiv de Paul Valéry: «La mer, la mer toujours recommencée», que ritma La consagración de la primavera. Hasta lleva la fruición linguística al punto de transcribir algunas canciones en créole, dialecto francés de las colonias del Caribe, en $E l$ reino de este mundo y El siglo de las luces.

Este procedimiento ofrece la doble ventaja de diversificar la musicalidad del texto y proyectar al lector hispanoamericano fuera de su espacio y su época. Es el refinamiento de un escritor que se entrega a la voluptuosidad de multiplicar las sensaciones, valiéndose de todos los recursos de una cultura exquisita. Todo es material apto para la alquimia del verbo. El esteta que hay en Carpentier sabe sacar partido de las 
artes que más han halagado su sensibilidad: la danza, la arquitectura, la pintura, la música. Por cierto, Carpentier sabe gozar de estas artes en sí mismas, por lo que son. Lo que interesa aquí es señalar cómo las va integrando en el relato para cargarlo de significación poética.

Para la danza, el ejemplo descollante es el texto de La consagración de la primavera, uno de cuyos narradores, el más importante, es una bailarina. Prioridad esencial porque, precisamente, lo que atrae sobre todo a Carpentier en la obra de Stravinsky es la danza sacra de la Rusia pagana, como depositaria de un sentido prístino. Pero también existe una segunda intención, desvelada por Vera, la bailarina, que «pensaba en quien se hubiese sacrificado (recordemos que la danza acompaña el sacrificio de una virgen) (...), convencido de que la sangre era necesaria para el advenimiento fecundo de nuevas primaveras en el mundo» (p. 187).

En cuanto a la arquitectura, desempeña a menudo un papel simbólico, y confiere dimensiones concretas a un estado de ánimo, a una nostalgia. Al volver de la selva, el hombre de Los pasos perdidos, añorante y desilusionado, no ve en la ciudad sino «columnas enfermas y edificios agonizantes» (p. 261); en la misma novela, la casa de la niñez es evocada, en cambio, como un refugio acogedor, con su «ancho soportal de columnas encaladas», "sus grandes muebles de madera oscura, armarios profundos y una araña de cristales biselados que se llena de pequeños arcoiris al recibir un último rayo de sol bajado de las lucetas azules, blancas, rojas, que cierran el arco del recibidor como un gran abanico de vidrio» (p. 98). Pero el carácter maravilloso que transmite la arquitectura a la realidad visible es sobre todo notable en otro lugar, cuando el narrador, en medio de la selva, descubre "unas moles de roca negra», de las que dice «que eran presencia y verdad de monumentos fabulosos», y empieza a describir esta «titánica ciudad» imaginando «una increíble catedral gótica (;una catedral gótica en la selva americana!), de una milla de alto», «algo tan fuera de lo real - morada de dioses, tronos y graderías destinados a la celebración de algún Juicio Final- que el ánimo, pasmado, no buscaba la menor interpretación de aquella desconcertante arquitectura telúrica, aceptando sin razonar su belleza vertical e inexorable» (pp. 178-179). Texto de antología, en el que sale patente el mecanismo transformador de la realidad en objeto maravilloso, a través de la imaginación del creador.

Aquella catedral imaginaria tiene su réplica en un cuadro obsesivo de El siglo de las luces que, como otro retrato de Dorian Gray, es el testigo de las peripecias de la vida de Esteban, la «prefiguración de los acontecimientos», dice el joven. En un acto de desafío, Esteban rompe el lienzo; pero cuando los personajes han desaparecido, el cuadro perma- 
nece en su lugar, sin asunto, «borrándose, haciéndose mera sombra», como dice la frase final de la novela.

La música, por su parte, está en todas las novelas: en Concierto barroco, desde luego; en $E l$ acoso, cuya acción se desenvuelve durante la ejecución de la Heroica de Beethoven; en Los pasos perdidos, en que algunas páginas evocan la Novena, del mismo compositor; en El recurso del método, con la Carta a Elisa o algunos compases de la sonata del Claro de luna, del mismo, o la Marcha fúnebre de Chopin. Pero es en La consagración de la primavera donde la música es aprovechada, más obviamente tal vez, para proyectar la situación más allá de lo real. La partitura de Stravinsky, según el novelista, tiene un poder mágico capaz de dar la impresión de un retorno a los elementos naturales de los orígenes del mundo. Dice Vera:

(...) nos iba conduciendo, la portentosa música de Stravinsky, a la Danza de la consagración, final en que la orquesta toda se fraccionaba, rompía con sus funciones tradicionales, creando una métrica nueva, ajena a toda periodicidad de acentos, donde los elementos sonoros, vistos en función de elementalidad - - y aquí volvían los instrumentos a ser maderas, cobres, tripas, pieles tensas, devueltos a su condición primera, a sus quehaceres en una liturgia tribal- eran llamados a expresar una enorme pulsión telúrica, marcada por paroxismos de expectación, espera, violencia, contenida o desbordada (p. 186).

\section{El más allá y LO MARAVILloso}

Los elementos evocados hasta ahora: lengua, cultura literaria y artística, constituyen, sin duda alguna, los signos exteriores de una interpretación maravillosa del mundo. Esta orquestación se apodera también de elementos de otra clase.

En el capítulo «Iniciación» de su primera novela, Carpentier escribe que la madre y el padre del joven Menegildo «tenían, por atavismo, una concepción del universo que aceptaba la posible índole mágica de cualquier hecho» (Ecué-Yamba-O, p. 56). Se describen escenas del vaudou, y Carpentier ilustra su novela con fotografías de imágenes sagradas y objetos de culto. El tema principal de este libro es el realismo mágico. Huellas de éste también se encuentran en $E l$ reino de este mundo, donde el monarca Henri Christophe, quien pretende haber impuesto el cristia nismo en la isla, teme, sin embargo, que lo hayan engualichado, clavando agujas en un muñeco parecido a él.

Cuando no se trata de magia, algunas acciones tienen, no obstante, 
un sentido esotérico. Así, en Los pasos perdidos, el viaje del protagonista es presentado como un viaje iniciático. Esteban ha sido iniciado en la Logia de los Extranjeros. El novelista vuelve a menudo a las prácticas secretas de la masonería, cuyo papel importante en América recuerda en El arpa y la sombra.

Pero es al Dios de los católicos hacia quien se vuelve el hombre perseguido de $E l$ acoso, ofreciendo su sufrimiento en un credo patético, imaginando los gemidos «con que los atormentados, los culpables, los arrepentidos, se acercaban a la Santa Mesa, para recibir el Cuerpo del Crucificado y la Sangre del Sacrificio Incruento» (p. 44). El misterio divino, con acompañamiento de la sinfonía de Beethoven, exalta trágicamente la realidad dolorosa de este hombre destinado a la muerte violenta.

Carpentier restituye también este maravilloso religioso, en su forma sincrética, mezclando el credo de los misioneros españoles con las creencias locales o africanas. Así, en el capítulo "Agnus Dei», de El reino de este mundo, Ti Noël vuelve a su forma humana después de haber sido metamorfoseado en ganso. En una de las fotografías que ilustran EcuéYamba-O se ve el texto de una oración a Santa Bárbara al lado de una estatuilla de Shango de Guinea, dios del trueno.

Vera recuerda:

(...) Aquí el surrealismo se da al estado bruto - me respondió (José Antonio): No hay que suscitarlo, no hay que buscarlo... Se nos presenta así, sin previo aviso, con la fuerza de una revelación. Y me mostraba la tienda donde a la sombra, junto/debajo de la altísima flecha del Sagrado Corazón, se vendían amuletos y objetos de hechicería sincrética: imanes atados con cintas, Piedras del Cielo, Hierros de Ogún, Hachas de Changó (...); oraciones para uso de ladrones y prostitutas, filtros del buen querer y frascos de la loción Amor vencedor, para usos propiciatorios que habrán de acompañarse de imploraciones al Anima Sola-, mujer atada, encordada, ardida en la infernal llamarada de sus celos, de la que existía una imagen gemela, idéntica, muy reverenciada aún ahora en la Catedral de Kiev (p. 336).

\section{Maravilloso y mitos}

En otro nivel, el texto de Carpentier se nutre con símbolos, mitos, alegorías. Carlos Santander recuerda con razón una frase del novelista: «Escojo cuidadosamente los nombres de los personajes, que responden siempre a una simbólica que me ayuda a verlos. Sofía, por ejemplo ( $E l$ 
siglo de las (uces), habrá de responder, según la etimología griega de su nombre, al conocimiento, al gay saber, etc. ${ }^{3}$. C. Santander no deja de observar que tal insinuación puede extenderse a muchos aspectos de la obra de Carpentier. La nueva ciudad de Los pasos perdidos se llama Santa Mónica, que es el nombre de la madre de San Agustín. Su gobernador es el socio de un tal fray Pedro, de nombre también simbólico. Carpentier menciona a menudo el Génesis a propósito de esta ciudad, que corresponde a la vez a la primera ciudad fundada por los conquistadores y a una «villa fuera de 1a Epoca» (p. 199), en la que se cifra el mito del origen, y entrevista por el protagonista y perdida por siempre jamás. En aquellos lugares del amanecer del mundo, el protagonista reconstruye con Rosario la Pareja Primitiva, en su «limpia desnudez». Por su parte, Esther P. Mocega-González ${ }^{4}$ da una interpretación religiosa de $E l$ acoso, donde la vida del hombre perseguido sería «una maravillosa representación de la vida del Hijo de Dios en su expiación por el tormento». Sanctis Spiritus, la ciudad donde nació el hombre acosado, cobra así un valor simbólico, y lo mismo el nombre de la prostituta, Estrella, quien se entrega al hombre que la quiere sinceramente.

Por lo demás, abundan los símbolos religiosos en la novelística de Carpentier.

Entre estas distintas interpretaciones destacaremos ahora un símbolo relacionado con la mujer. A partir de la primera novela, la mujer es refugio y origen. Para Esteban, es «árbol de vida» (p. 304). Por tanto, es madre; es virgen, como representante de la pureza primera, y también destinada a la unión carnal. Esta es la doble naturaleza que tiene en $E l$ siglo de las luces: Sofía, con la que Esteban comparte los mismos juegos en su niñez, es la única que despierta en él un amor completo, espiritual y sexual a la vez. Ahí se ve, pues, la mujer unida a la infancia. En otra parte, metafóricamente, es ella también la naturaleza protectora y la que da el primer alimento. La Longina de Ecué-Yamba-O, así como la Rosario de Los pasos perdidos, son de alguna manera las mujeres naturales que se oponen a las artificiales de la ciudad. A través de la mujer, se viene afirmando el mito de la naturaleza como fuente de vida y paraíso perdido, mientras que la ciudad es la morada de la muerte. En ambos casos, se trata de la mujer americana auténtica; el viaje del hombre «civi-

${ }^{3}$ C. Santander, «Lo maravilloso en la obra de Alejo Carpentier», en H. F. Giacoman, Homenaje a Alejo Carpentier (New York: Las Americas Publishing Co., 1970), pp. 101-144).

${ }^{4}$ E. Mocega González, «La simbología religiosa de $E l$ acoso de Alejo Carpentier», en Anales de la literatura hispanoamericana, núms. 2-3 (Madrid, 1973-1974), pp. 521-532. 
lizado» a la selva y la mujer encontrada en ella cobran, pues, en Los pasos perdidos especialmente, todo su valor simbólico.

Y quizá didáctico: conviene tal vez pensar, en efecto, que no se trata ahí de cualquier hombre civilizado, sino del hombre hispanoamericano. $\mathrm{Y}$ en esto se revela la problemática planteada por Carpentier, definido por Klaus Müller-Bergh como «cubano por nacimiento, esencialmente europeo por educación y profundamente hispanoamericano por inclinación» (Alejo Carpentier. Estudio biográfico-crítico). De ahí el sentido metafórico de los viajes de ida y vuelta entre América y Europa emprendidos por Carpentier y sus personajes, en el espacio, en la cultura, en el tiempo.

E1 tiempo elegido por Carpentier es muchas veces el siglo XVIII, pero este tiempo abarca también desde la conquista hasta la era moderna. Algunas novelas, Concierto barroco y El arpa y la sombra, por ejemplo, conjugan presente y pasado, deleitándose el autor en el anacronismo, sin duda para materializar por la escritura esta clase de eternidad maravillosa que el hombre conoce solamente gracias al sueño, la ficción o la fe.

Este caminar por el tiempo y las culturas, buscando un ser problemático, ha provocado reflexiones angustiadas en algunos escritores. En Carpentier, nada de eso, porque se le ocurre más bien que la realidad es un espectáculo maravilloso.

\section{DeSDE LA REALIDAD hasta El ESPECtÁculo marayilloso}

A Carpentier le gusta sobremanera el espectáculo. El reino de este mundo, además del epígrafe, sacado de una comedia de Lope de Vega, o la presencia de una actriz, muestra hasta la evidencia el placer del narrador en la descripción de trajes y palacios. La escena principal de $E l$ acoso se desarrolla en una sala de conciertos. Los niños de $E l$ siglo de las luces se divierten disfrazándose. Concierto barroco es una evocación abigarrada a más no poder del carnaval de Venecia y de una sala cargada de adornos, donde Vivaldi dirige una orquesta. La consagración de la primavera multiplica pormenores acerca de la organización de un ballet, con sus sesiones de ejercicios en la barra y ensayos.

Carpentier ofrece un espectáculo. Como lo sugiere Fernando Alegría, «Carpentier escribe (...) para un público europeo. Le domina la obsesión de probar (...) que en América existe un depósito activo de fuerzas mitológicas -a veces dormidas bajo una capa de occidentalismo superficial- cuyo funcionamiento, en el terreno del arte, da realidad a todo un sistema de símbolos que la cultura europea no concibe sino en plano 
estático, abstracto. Lo que en la tradición surrealista es caos organizado, en su obra es un caos natural y auténtico» ${ }^{5}$. En El arpa y la sombra, Cristóbal Colón declara que cuanto ha escrito es falso, que aquí, es decir, en América, nada se parece a lo que se ve en Europa.

Así, en América, en relación con Europa, todo es multiplicado, y la obra de Carpentier refleja esa hipertrofia. Un dictador casi endiosado, por ejemplo, impone el culto de su mujer (El recurso del método); el palacio que manda edificar el mismo es descomunal y reproduce, más grande que el original, un monumento extranjero, con una estatua tan colosal que ésta se pierde en las alturas de la cúpula. Cuando le hablan de las vírgenes honradas por la hagiografía francesa, el dictador suelta una retahíla interminable de vírgenes americanas. Todo es más grande, hasta la irrisión, como durante el auto de fe de libros, cuando van a parar a la hoguera cuantos volúmenes llevan en el título el adjetivo rojo, emblema de la subversión: Le lys rouge, Le rouge et le noir, etc. La naturaleza no se puede medir por la escala europea, como se ve con la muerte del general Hoffmann, sepultado vivo en el barro movedizo de la selva tropical; o el viaje de Colón, en El arpa y la sombra.

Carpentier ha tenido siempre la conciencia de una cultura mestiza, y elabora un arte original, doble, que llega a su más alto grado de perfección, desde este punto de vista, en La consagración de la primavera y Concierto barroco. En la primera novela, admirada por el sentido esotérico con el que unos negros interpretan danzas tradicionales, Vera tiene la ocurrencia de contratarlos para la representación de un ballet de Stravinsky. Presiente un encuentro extraordinario y novedoso entre ese ballet imaginado a partir de danzas folklóricas primitivas rusas y la inspiración animista de los negros. Concierto barroco realiza la fusión del arte de Vivaldi y el desenfreno delirante de Filomeno, quien acompaña la pieza dirigida por el compositor italiano, con los utensilios más variados de una batería de cocina, con grandes aplausos de Scarlatti y Haendel, literalmente fascinados por la vitalidad de ese «diablo de negro», así llamado por uno de los compositores pasmados. De hecho, lo mismo que, con dos años de diferencia, Vivaldi primero y después Rameau, con Moctezuma (1733) y Les Indes galantes (1735), respectivamente, arreglaban, según la fantasía europea, el exotismo del Nuevo Mundo, Carpentier, recorriendo a la inversa el mismo camino, introduce en la música europea el recurso de instrumentos autóctonos americanos. Este Concierto barroco simboliza, en efecto, la fantástica confluencia de dos manifestaciones

${ }^{5}$ F. Alegría, «Alejo Carpentier: realismo mágico, en Giacoman, op. cit., pp. 33-69. 
musicales de orígenes distintos. Pero, en la novela, la última palabra la tiene América: termina el relato con un solo de trompeta ejecutado por Louis Amstrong.

\section{VII. ¿QUÉ REALIDAD MARAVILLOSA?}

Del análisis anterior se infiere que, al definir a América como una realidad maravillosa, Carpentier definió de rechazo, al parecer, su propia concepción del arte de novelar. Pero, como al mismo tiempo pretendía encerrar en esa fórmula la realidad americana, es lícito preguntarse qué tipo de realidad se refleja en ese «gran teatro del mundo» hispanoamericano.

¿No será europea la visión de Carpentier? ¿No proviene ésta del tradicional asombro de los europeos, que desde el descubrimiento no han dejado de considerar a las Américas tierras fabulosas? La larga permanencia de Carpentier en París y su cultura esencialmente europea no son ajenas, por supuesto, a la formación de su sensibilidad. $Y$ cuando Carpentier proclama la necesidad, para un hispanoamericano, de cultivarse, está pensando en una cultura europea e hispanoamericana a la par. Todo está en saber cuál es la parte que domina en él. Los testigos no están de acuerdo. Varios críticos le han reprochado su manera de ver, demasiado influida, según ellos, por una fantasmagoría propia de escritores, artistas, viajeros o historiadores europeos. Hemos dicho antes que casi todas sus fuentes corren desde España, Italia, Inglaterra, Alemania y, sobre todo, Francia. Las citas de autores hispanoamericanos o indígenas son escasísimas en su obra novelesca. Otros críticos, en cambio, hacen hincapié en la actitud americanista del escritor cubano. Lo uno no quita lo otro. Esta polémica no hace sino evidenciar, tal vez, lo que Rodríguez Monegal ${ }^{6}$ llamó la «doble mirada» de Carpentier. Y con esta dualidad se toca la problemática delicada de la identidad hispanoamericana, y resulta difícil, para no decir imposible, salir del dilema. Como hispanoamericano, en sus viajes por Haití o Venezuela, Carpentier ha sentido el hechizo del espectáculo. Como hispanoamericano también se ha apasionado por la historia y el porvenir, las creencias, las artes del continente mestizo donde nació. Pero, como hijo carnal y espiritual de europeos, ha proyectado sobre esta realidad la admiración maravillada de viajeros y estetas.

'E. Rodríguez Monegal, "Lo real y lo maravilloso en $E l$ reino de este mundo» (en Narradores de esta América, de E. R. Monegal, Buenos Aires: Alfa, 1975, t. 2, pp. 64-98). 
Mejor aún: ha comprobado que América vive al mismo tiempo en la edad de los pueblos primitivos y en la era atómica, con todas las etapas intermedias que esto significa, y que bastaban pocas horas de avión para pasar de una a otra; que el continente latinoamericano es un inmenso «crisol» - para emplear un término consagrado-, en el que se funden razas y culturas y existe una humanidad original. Esto es lo maravilloso de esta realidad.

Por cierto, esta visión cósmica no tiene en cuenta las diferencias entre la América tropical, evocada por él, y las otras, ni los puntos de vista de categorías de hombres que no tienen su cultura, o que han pintado en sus obras realidades hispanoamericanas nada maravillosas; y esto a pesar de haber aludido, en La consagración de la primavera, a una era social nueva.

Sacaremos de esta misma novela, como una definición dinámica de esta realidad maravillosa, según Carpentier, en su esperanzada potencialidad:

Si bien se miraba, todo esto era maravilloso y formaba parte del cúmulo de maravillas que poco a poco se mostraban a quienes quisieran otear en profundidad el mundo latinoamericano, donde lo terrible de ciertas contingencias políticas, el horror de las dictaduras militares o civiles, se inscribían en lo pasajero y transitorio de una historia turbulenta, en tanto que permanentes eran los portentos de lo circundante, de lo que era de la naturaleza, del ambiente y de la esencia auténtica del hombre nacido de los más vivificantes mestizajes que hubiesen consignado las crónicas del planeta (p. 447).

[Ponencia leída el 24 de abril de 1981, en un Homenaje a Alejo Carpentier realizado en la Sorbona.] 